\title{
Augmented Reality for Underwater Activities with the Use of the DOLPHYN
}

\author{
Abdelkader Bellarbi ${ }^{1}$, Christophe Domingues ${ }^{2}$, Samir Otmane ${ }^{2}$, Samir Benbelkacem ${ }^{1}$ \\ and Alain Dinis ${ }^{3}$ \\ ${ }^{1}$ Centre de Développement des Technologies Avancées CDTA, Algiers, Algeria \\ ${ }^{2}$ IBISC EA 4526- University of Evry, France \\ ${ }^{3}$ VirtualDive SAS, Versailles, France \\ ${ }^{1}\{$ abellarbi, sbenbelkacem\}@cdta.dz, \\ ${ }^{2}$ \{firstname.lastname\}@ibisc.univ-evry.fr \\ adinis@virtualdive.com
}

\begin{abstract}
The objective of this work is to introduce Augmented and Mixed Reality technologies in aquatic leisure activities. We have proposed a new device which is autonomous, mobile and easily transportable by one person. It can also be easily installed, equipped with GPS and wireless systems, and has positive buoyancy. The device will be used at water surface as well as underwater using a tuba. Moreover, the device is equipped with one (can be upgraded for more) video camera pointing downwards. Augmented Reality contents combining actual underwater images with 3D animated images will be one of the preferred ways to use the device.
\end{abstract}

Keywords-Augmented Reality, Underwater, Human machine Interaction

\section{INTRODUCTION}

The introduction of virtual and mixed realities in aquatic leisure activities constitutes a technological rupture when compared with the status of related technologies [1] [2] [3]. With the extension of Internet to underwater applications, the innovative character of the project becomes evident, and the impact of this development in the littoral and beach tourism may be considerable. In fact, there are recent developments to extend the use of computers and computer components, such as the mouse, to underwater uses [4] [5]. A previous work using the Dolphyn [6] presented in [7] had introduced an underwater augmented reality (AR) game interface. In this paper, we present an extended work for underwater activities using AR.

\section{DOLPHYN DESCRIPTION}

The DOLPHYN is using an $\mathrm{x} 86$ tablet running Windows 7 that is connected to various devices: user interface device, GPS, sensors (thermometer, flow-meter) and a WIFI device (see figures 1, 2, 3 and 4).

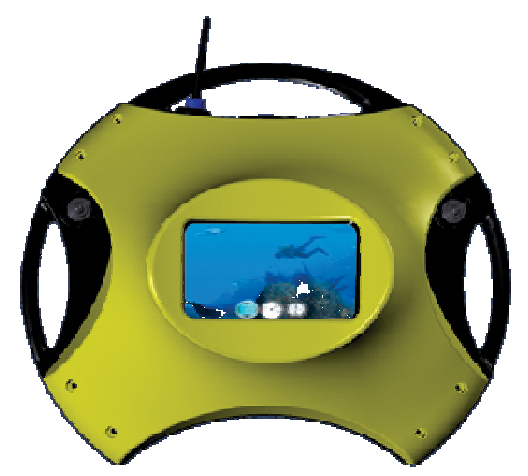

Figure 1: Dolphyn 3D Model

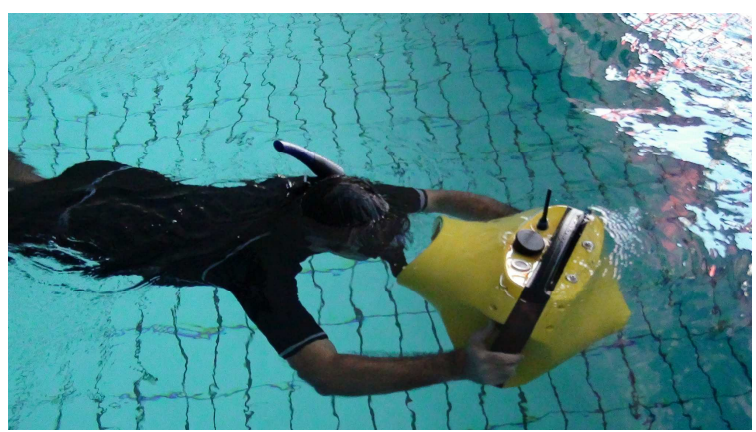

Figure 2: Dolphyn in the Swimming pool

Two internal modules compose the DOLPHYN:

Waterproof case which contains the tablet;

Waterproof electronic case that is used to manage all connected devices. 


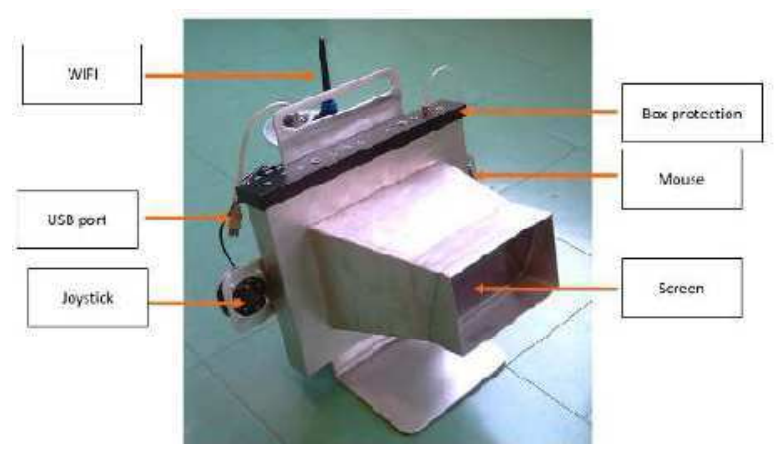

Figure 3: Internal -back view

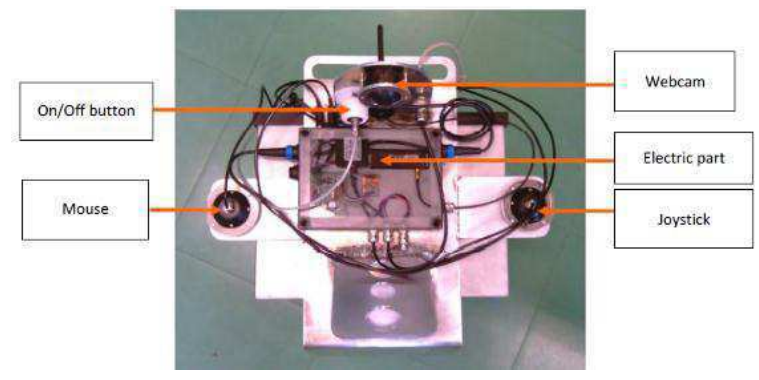

Figure 4: Internal -front view

To power the tablet, the user must press the white and black button located on the top of the device. A hydraulic system is used to transmit the movement of an actuator button in front of the on/off button of the tablet. To interact with the tablet, there are two joysticks on the left and right of the prototype. Each one is equipped with a center button for filling the function of a mouse click. The default configuration used is as follows:

- Right Joystick: Mouse moves. The button is acting as a mouse left click;

- Left joystick: Use to play games. It is acting as a joypad. However the central button is acting as the mouse right click;

- Flow meter: to measure the displacement of the device. It is acting as a z-joypad.

\section{CONTENT EXAMPLES}

Many type of content is currently being developed for this device. We have decided to present a Virtual Reality (VR) and an Augmented Reality (AR) contents.

A virtual reality game has been developed [6] that we call Nautilus Quest. Nautilus Quest aims to explore the underwater world of the Mediterranean in an entertaining and educational manner (Figure 5). The game can be installed on several devices allowing for multiplayer gaming. It offers three different missions simultaneously:

- Collection of waste (learn to respect the ocean);

- Underwater Photo Safari (discover the local flora and fauna);
- Search for treasures (fun missions).

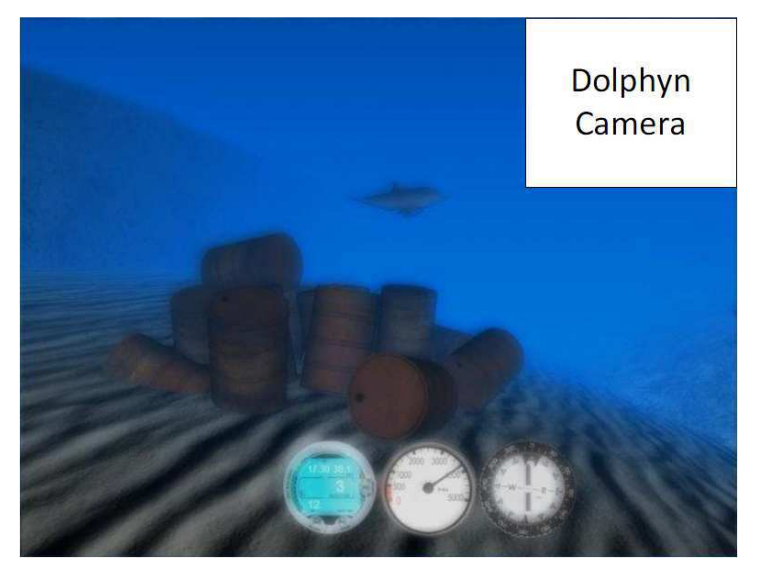

Figure 5: Nautilus Quest - The webcam allows the user to view his/her real trajectory on the sea or the swimming pool

\section{AR SERIOUS GAME DESCRIPTION}

The game idea is to explore the ocean and to discover its different species through surviving, performing tasks and collaboration [7]. The main objective of the game is educational. It allows the divers to know the different underwater creatures, and how to preserve their environment. The solution is to allow the diver to see 3D virtual species using display device. Thus, augmented reality techniques can be used to develop this game.

To ensure a good insertion of virtual objects in the underwater scene, the knowledge about the position of the camera is needed. So, vision-based techniques can be used to calculate the position and the orientation of the camera. This consists on the calculation of intrinsic and extrinsic parameters of the camera. Our objective is to calculate the camera's intrinsic parameters corresponding in the underwater world. For the extrinsic parameters, it corresponds to the calculation of the pose of the camera. Among the existing techniques, marker-based methods seem to be appropriate to underwater context. These methods measure the relative position and orientation between a camera and markers (transformation matrix marker/camera).

In our case, ArtoolkitPlus (Augmented Reality Toolkit Plus) [8] is used to develop augmented reality applications using markers. The latter are placed in the diving site (Figure 6). When the diver uses the Dolphyn's camera and dives into the site, the markers are recognized and the Dolphyn is located. 


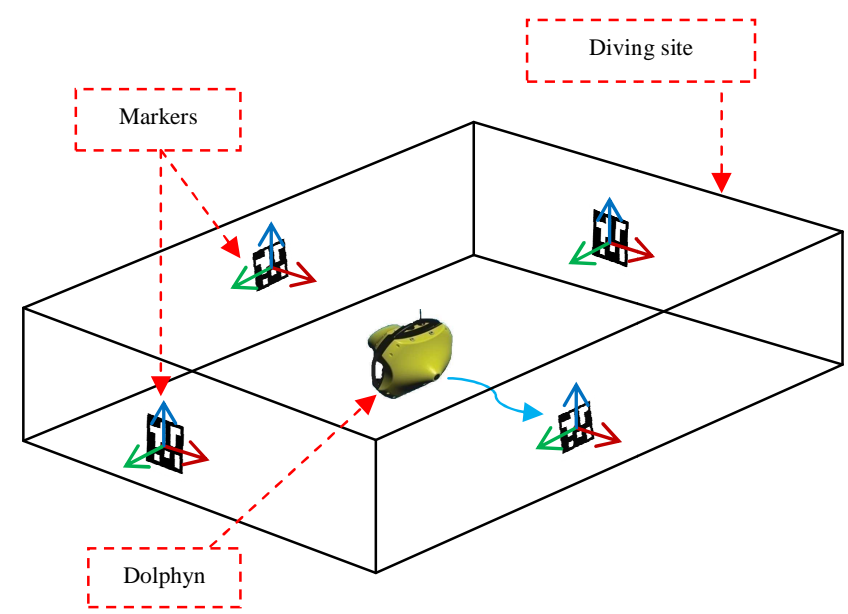

Figure 6: Placement of markers in the diving site

The recognition of the markers enables the Dolphyn's user (diver) to view virtual fishes, virtual marine-plants and virtual submarines.

\section{A. Camera calibration}

Due to the lens thickness used to protect the Dolphyn's camera from the water pressure, captured images suffer from high distortion (Figure 7), for this purpose, a calibration step (calculation of intrinsic parameters) in prior is essential.

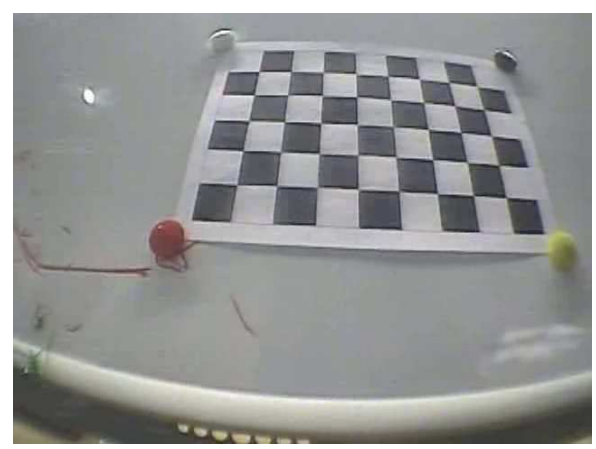

Figure 7: Captured image the Dolphyn's camera

In our case, the method of Zhang [9] implemented in OpenCV is used to calibrate the camera. So, a calibration grid of 9x6 is employed. The calibration results (intrinsic parameters) are, then, used to calculate the extrinsic parameters (Transformation Matrix).

\section{B. Game Scenario}

In our case study, two scenarios of game are established:

The first one consists in protecting fishes and plants by eliminating submarines that kill the fishes and cut the plants. The player moves underwater and handles a Dolphyn device equipped with a camera. The player displays fishes, plants and submarines in augmentation form (see Figure 8, 9 and 10). Particularly, the augmented fishes move in various directions and speeds.
The principal goal is to eliminate the moving submarines by pulling with the virtual missiles using the Dolphyn's joystick.

The player is subjected to some constraints. The number of missiles to shoot is limited. So, the player should be more accurate as possible when he aims the submarines.

Also, the player should not shoot the fishes neither the plants. If the player is hit by a missile from a submarine, his energy level decreases. The player is considered loser when his energy level is zero. Else, if all the submarines are eliminated, the player is winner.
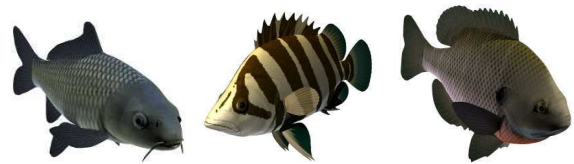

Figure 8: Some 3D fish

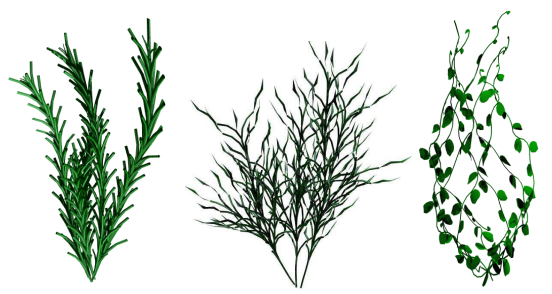

Figure 9: Some 3D Virtual Marine Plants

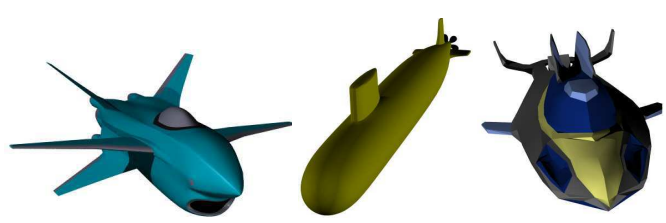

Figure 10: Some 3D submarines

The second scenario is educational. The user may see a variety of fishes and plants existing underwater. Here, annotations (e.g. fish's name, origin) are displayed on each virtual element. For instance, when a virtual fish is visible by the Dolphyn's camera, the annotation is placed beside this fish. To avoid overlaps, the user can hide the annotation.

\section{Examples of Scenarios}

In this section, some examples of our application testing are presented. Figures 11 and 12 give the first game scenario, while, figure 13 shows the second scenario (the educational part). 


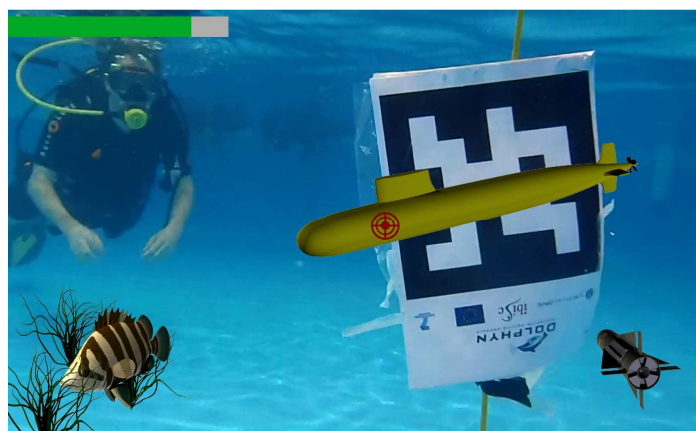

Figure 11. The player fires the submarine

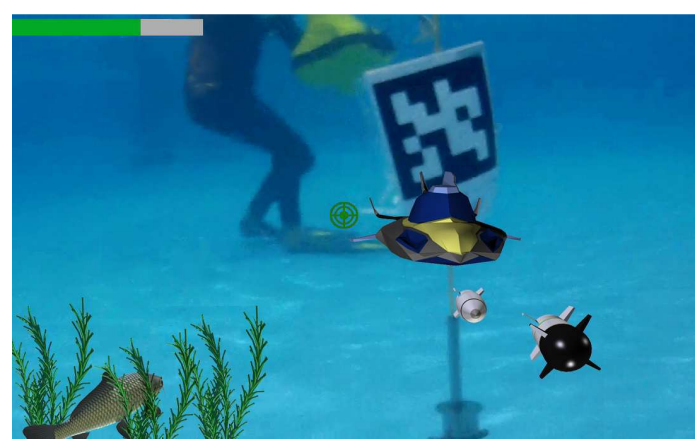

Figure 12. The submarine shoots the player

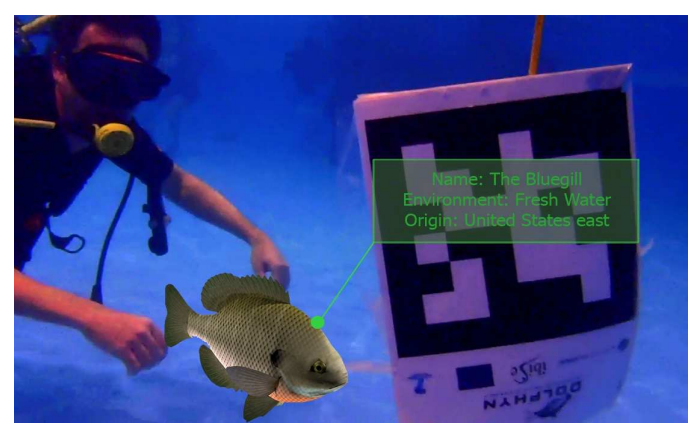

Figure 13: Fish annotation

\section{CONCLUSION}

In this paper, augmented reality for underwater activities application using the Dolphyn devices is presented. This system offers for divers an augmented reality interactive interface, in order to help him to perform different tasks.

The positive results of this work, give us new ideas to develop more sophisticated applications and to enhance new technical aspects of the hardware prototype. As well, we plan to extend our knowledge to apply the underwater AR in other applications as underwater maintenance using AR.

\section{ACKNOWLEDGEMENTS}

This project (Digital Ocean - FP7 262160) is a collaborative project funded through European Community's Framework Program FP7.

\section{REFERENCES}

[1] A. Dinis, N. Fies, N. Cheaib, S. Otmane, M. Mallem, A. Nisan, J.M. Boi. DIGITAL OCEAN: "A National Project for the creation and distribution of Multimedia Content for Underwater Sites". Proc. Ofthe 14th International Conference on Virtual Systems and Multimedia, Dedicated to Digital Heritage, VSMM'08, pages 389 396, Limassol Cyprus, October 2008.

[2] R. L. Ashok and D. P. Agrawal. "Next-Generation Wearable Networks", In IEEE Computer 36, 31-39, November 2003.

[3] Bruce Macdonald. A haptic interface for mobile devices, In proceedings of the 17th Australia conference on ComputerHuman Interaction, OZCHI '05, Narrabundah, pages 1-3, 2005.

[4] A. Vasiljevi, Borovi B. and Vuki Z., "Augmented Reality in Marine Applications", In Brodogradnja 62, 2, 2011

[5] L. Blum, W. Broll, S. Müller, "Augmented Reality under water", SIGGRAPH '09, ACM New York, NY, USA 2009

[6] C. Domingues, S. Otmane and A. Dinis, "A new Device for Virtual or Augmented Underwater Diving", in "IEEE Symposium on 3D User Interface (3DUI 2012), Orange County, CA : United States (2012)".

[7] Abdelkader Bellarbi, Christophe Domingues, Samir Otmane, Samir Benbelkacem, and Alain Dinis. "Underwater augmented reality game using the DOLPHYN", In Proceedings of the 18th ACM symposium on Virtual reality software and technology VRST'12, pp. 187-188. ACM, 2012.

[8] Wagner, D., Schmalstieg, D. "ARToolKitPlus for Pose Tracking on Mobile Devices", Proceedings of 12th Computer Vision Winter Workshop (CVWW'07), pp. 139-146, 2007.

[9] Z. Zhang, "Flexible camera calibration by viewing a plane from unknown orientations". International Conference on Computer Vision, volume 1, page 666, Corfu, Greece. 1999. 